\title{
ESTADO PATRIMONIAL E GESTÃO DEMOCRÁTICA DO ENSINO PÚBLICO NO BRASIL ${ }^{1}$
}

\author{
ERAsto Fortes MENDONÇA*
}

\begin{abstract}
RESUMO: O artigo aborda o tema da Gestão Democrática do Ensino Público no Brasil. Busca identificar como os sistemas de ensino dos estados, do Distrito Federal e dos municípios das capitais organizaramse para responder ao ordenamento constitucional que estabeleceu a gestão democrática como princípio do ensino público e em que níveis adaptaram suas legislaçôes e normas, sua estrutura administrativa e seu funcionamento às demandas por participação. Analisa as concepções de gestão democrática à luz das categorias participação, processo de indicação de diretores, constituição e funcionamento de colegiados, descentralização e autonomia. Aponta estudos e pesquisas recentes sobre os esforços e as resistências verificados em processos de implementação de mecanismos de gestão democrática em diversos sistemas de ensino. Considera que a gestão democrática é adotada pelo Estado para alcançar seus objetivos estratégicos. Analisa as dificuldades decorrentes da implantação desses mecanismos que, pressupondo forte participação da sociedade, é patrocinada por um Estado fortemente marcado por ordenamentos patrimonialistas.
\end{abstract}

Palavras-chave: Educação e Estado; Patrimonialismo; Gestão democrática.

\section{Introdução}

A educação brasileira experimentou uma democratização tardia. Criada e cevada para servir à elite, chegou ao fim do século XX empunhando bandeiras há muito superadas em países de tradição democrática. As influências liberais, que por aqui aportaram, adaptaram-se aos interesses de grupos, dando origem a uma forma especial de liberalismo calcado mais nesses agregados sociais que no povo. A cultura política autoritária predominou, intercalada por espasmos de democracia. Nesse quadro, a

* Docente da Faculdade de Educação da Universidade de Brasília e Pesquisador do Grupo de

Pesquisa em Política e Administração da Educação Básica. E-mail: erastofm@uol.com.br 
educação pública foi se desenvolvendo, administrada por um Estado tutelador, superior ao povo. A democratização da educação brasileira passou por vários estágios, tendo sido compreendida, inicialmente, como direito universal ao acesso e, posteriormente, como direito a um ensino de qualidade e à participação democrática na gestão das unidades escolares e dos sistemas de ensino. Em 1988, movida por inúmeros acontecimentos que propeliram a participação popular, a Constituição Federal estabeleceu como um dos princípios do ensino público brasileiro, em todos os níveis, a gestão democrática. Ao fazê-lo, a Constituição institucionalizou, no âmbito federal, práticas ocorrentes em vários sistemas de ensino estaduais e municipais. Algumas dessas práticas são amparadas por instrumentos legais produzidos pelas respectivas casas legislativas ou pelos executivos locais. Considerando que esse conjunto de experiências, realizadas a partir das realidades locais e regionais, comportava um levantamento que permitisse uma análise das iniciativas adotadas, interessei-me em pesquisar como os sistemas de ensino se organizaram para responder ao ordenamento constitucional e em que nível adaptaram suas legislaçóes, sua estrutura de poder e seu funcionamento às demandas por participação que atingiram o ensino público nas últimas décadas.

A pesquisa ${ }^{2}$ baseou-se em dois tipos de levantamento. $\mathrm{O}$ primeiro, de natureza bibliográfica, compilando estudos sobre a temática da gestão democrática do ensino público, especialmente aqueles produzidos após a promulgação da Constituição Federal de 1988. O segundo, de natureza empírica, a partir de 133 consultas formuladas às instâncias executiva, legislativa e normativa das 27 unidades da Federação e dos 26 municípios das capitais, reunindo 363 documentos (196 de âmbito estadual e 167 de âmbito municipal) que expressam as visões institucionais sobre o tema pesquisado.

O universo da pesquisa foi a educação básica, nos níveis fundamental e médio, sob a administração dos sistemas estaduais e dos municípios das capitais, sendo excluídos da análise os procedimentos adotados na educação infantil e na educação superior. $\mathrm{O}$ objeto da pesquisa foi o tema da gestão democrática do ensino público e as questões suscitadas por ele. Os dados empíricos foram utilizados, nesse sentido, não para descrever ações desenvolvidas e compará-las sistema a sistema, mas para permitir a análise de questóes sugeridas pelo processo de institucionalização dos mecanismos adotados como resposta à determinação constitucional. Os dados obtidos a partir dos dois levantamentos mencionados foram sistematizados a partir de cinco categorias: mecanismos de provimento de diretores, constituição e funcionamento de colegiados, participação, descentralização e autonomia. 
Os instrumentos de pesquisa encaminhados incluíam uma sugestão de roteiro para coleta de informaçôes. ${ }^{3}$ Foi atendido um total de 63 solicitações, perfazendo, portanto, um índice de $47 \%$ de consultas deferidas. ${ }^{4}$ Os materiais recebidos em atendimento às consultas formuladas variaram desde respostas objetivas ao roteiro sugerido, até o envio de ampla documentação ilustrativa sobre o tratamento que os sistemas têm dispensado ao princípio da gestão democrática do ensino público. Em números, foram coletados 363 documentos, entre leis complementares, leis estaduais e municipais, decretos estaduais e municipais e projetos de lei das secretarias estaduais e municipais de educação e das assembléias legislativas e câmaras municipais; portarias, resoluções, instruçôes normativas e editais das secretarias estaduais e municipais de educação; resoluções, deliberaçôes, indicaçôes, pareceres e pronunciamentos dos conselhos estaduais de educação. Além desse vasto material legislativo e normativo, foram coletados inúmeros documentos institucionais como propostas pedagógicas, planos plurianuais de educação, regimentos escolares, livros e brochuras contendo programas e projetos educacionais, cartilhas, reportagens, conferências.

Uma questão fundamental norteou a pesquisa: como os sistemas de ensino brasileiros se organizaram para responder ao princípio da gestão democrática e como é possível funcionar uma política educacional que, supondo forte participação da sociedade, é patrocinada por um Estado que tem sua estrutura marcada por ordenamentos patrimonialistas? 5

\section{II - A intenção e o gesto: o que dizem os dados empíricos}

É importante mencionar que as respostas encaminhadas à pesquisa denotam, em alguns casos, uma compreensão exageradamente ampla da gestão democrática do ensino público. Quase tudo que tem relação com a ampliação de direitos educacionais é entendido pelos administradores dos sistemas como mecanismo de gestão democrática. Outro dado de caráter geral diz respeito a leis específicas sobre gestão democrática. Esses instrumentos legais constituem-se como manifestação legislativa mais completa do entendimento das autoridades sobre a maneira pela qual a norma constitucional se aplica ao sistema público de ensino de sua alçada. No entanto, somente quatro unidades da Federação e um município de capital $^{6}$ possuem leis que dispõem sobre a gestão democrática. Mesmo assim, nenhuma dessas leis trata a temática com extensão suficiente para justificar o título dado a elas, restringindo-se, em todos os casos, apenas a alguns de seus aspectos e mecanismos. 


\section{Participação}

Vários estudos sobre gestão democrática abordam a participação como temática principal. ${ }^{7}$ Ao abordar aspectos da gestão democrática do ensino público ligados à participação, foi possível constatar que, ao contrário do que se idealiza sobre a convivência entre membros da comunidade escolar, os mecanismos adotados pelos sistemas não lograram pôr termo à guerra entre segmentos. Diretores, professores e funcionários, com prevalência dos primeiros, ainda monopolizam os foros de participação. A escola pública ainda é vista pelos usuários como propriedade do governo ou do pessoal que nela trabalha. $\mathrm{O}$ professor comporta-se como dono do seu cargo, dos alunos e de suas classes. O diretor funciona como guardião dessa concepção, evitando interferências de servidores e de pais. As legislações têm funcionado como mecanismos reguladores dessa prevalência, uma vez que impóem critérios de proporcionalidade na participação aos segmentos organizados da comunidade escolar. Isso não impede, no entanto, que permaneçam existindo comportamentos e atitudes de dominação dos docentes sobre os demais membros, sob argumentos que, em geral, se baseiam em questões ligadas à competência pedagógica. Apesar das várias tentativas legais de correção das distorções que privilegiam os segmentos docente e administrativo, observam-se algumas legislações que chegam a legitimar a restrição à participação dos pais e responsáveis.

\section{Mecanismos de escolha de diretores}

A forma de escolha de dirigentes escolares talvez seja o tema que mais tem motivado pesquisadores na produção de reflexões teóricoconceituais e de investigações empíricas sobre a gestão democrática da educação, especialmente a análise de processo de eleições e das experiências vivenciadas em alguns sistemas de ensino. ${ }^{8} \mathrm{~A}$ importância desse elemento de gestão democrática é compreensível pela vinculação do processo eleitoral com a democracia e pelo espaço que esse mecanismo ocupou como bandeira de luta dos movimentos sociais. No início da década de 1980, a discussão foi polarizada pela questão da indicação de dirigentes escolares, de tal modo que a luta pela implantação de eleições de diretores fez com que a ampla temática da gestão democrática fosse, de certa maneira, reduzida a esse mecanismo. Os métodos centralizados de administração, o papel exercido pelos diretores de escola e os processos de indicação política de pessoas não identificadas com a unidade escolar 
exerceram influência decisiva na organização em torno da idéia de eleições como processo de provimento do cargo de diretor.

Os dados recebidos dos sistemas de ensino permitiram identificar quatro formas de provimento do cargo. O provimento por indicação, em que é livre a nomeação por autoridade do Estado, inclusive quando o nome do indicado é o resultado de pressões político-partidárias. $\mathrm{O}$ concurso engloba os procedimentos que aplicam o concurso público de provas e títulos para escolha e nomeação dos primeiros colocados. Provimento por eleição é aquele em que o nome do escolhido para ocupar o cargo de diretor de escola é resultado de processo em que a manifestação da vontade dos segmentos da comunidade escolar é manifestada pelo voto. Seleção e eleição são os processos que adotam eleição de candidatos previamente selecionados em provas escritas.

As informações recebidas dos sistemas conjugadas com os dados divulgados pela investigação nacional conduzida pela Anpae (Dourado \& Costa, 1998) permitiram a construção de um quadro nacional mais completo sobre os mecanismos adotados para provimento do cargo de diretor escolar entre os anos de 1996 e 1998. Esses dados permitem constatar que o mecanismo de provimento do cargo de diretor mais adotado no país é o da eleição (53\%), com considerável participação dos municípios. A indicação é o segundo mecanismo mais utilizado no conjunto dos sistemas de ensino, com predominância nos sistemas estaduais (44\%). O processo de seleção seguida de eleição é realizado em apenas $10 \%$ dos sistemas de ensino, só ocorrendo nos estados. O concurso público, com apenas duas ocorrências em todo o país, está restrito ao estado de São Paulo e sua capital. O percentual de $34 \%$ relativo à ocorrência do processo de indicação por escolha da autoridade revela, também, que, após mais de dez anos da promulgação da Constituição Federal, dezoito sistemas de ensino ainda não lograram estabelecer qualquer tipo de procedimento mais democrático para a escolha de seus diretores.

Os mecanismos de provimento do cargo de diretor escolar são reveladores das concepções de gestão democrática adotadas pelos sistemas de ensino. As escolas públicas brasileiras tradicionalmente tiveram seu provimento efetivado por nomeação do governador ou do prefeito, em geral a partir de indicações feitas pelos titulares das Secretarias de Educação ou das lideranças político-partidárias das respectivas regiōes. A interferência política no ambiente escolar permitiu que o clientelismo político tivesse, na escola, um campo fértil para seu crescimento. Para o político profissional, ter o diretor escolar como aliado político é ter a possibilidade de deter indiretamente o controle de uma instituição 
pública que atende diretamente parte significativa da população. Para o diretor, gozar da confiança da liderança política é ter a possibilidade de usufruir do cargo público. Estabelecem-se, desta maneira, as condições de troca de favores que caracterizam o patrimonialismo na ocupação do emprego público. Essa forma de provimento, que denominei indicação, baseia-se na confiança pessoal e política dos padrinhos e não na capacidade própria dos indicados, ficando distante da ordenação impessoal que caracteriza a administração burocrática. A exoneração segue, nesse sentido, a mesma lógica. $\mathrm{Na}$ medida em que o beneficiado com o cargo perde a confiança política do padrinho, a exoneração é acionada como conseqüência natural, como o despojamento de um privilégio.

A crítica ao processo de indicação política de diretores escolares ensejou a busca de mecanismos alternativos como o concurso público e as eleições. No concurso público, a qualificação do candidato é medida por prova e certificada por diploma. Esses fatores, aliados ao critério da impessoalidade na escolha de quem será nomeado, aproximam o diretor da figura do funcionário burocrático. Apesar do inegável avanço que possa significar a aplicação do concurso em relação aos procedimentos de indicação política, não é sem crítica que esse mecanismo se mantém no estado de São Paulo e em sua capital. Dentre essas críticas, destaco, pela sua pertinência, aquelas que assinalam que a escola que recebe o diretor nomeado fica impedida de opinar sobre quem considera mais capacitado para dirigi-la e as que lembram que o concurso não consegue medir a capacidade prática dos candidatos ou a sua liderança para conduzir os processos político-pedagógicos que se passam no interior da escola. Uma vez que o concurso pode ser justificado como medida de democratização, como superador do processo de indicação, teria, também, servido para retardar e dificultar a tomada de consciência dos educadores sobre a necessidade de eleiçôes como mecanismo mais radical de democratização da escola.

A eleição de diretores é o processo que melhor materializou a luta contra o clientelismo e o autoritarismo na administração da educação. Os argumentos em defesa desse processo giram em torno de seu caráter democrático e da possibilidade de aquilatar a capacidade de liderança política dos candidatos, abarcando, dessa maneira, uma dimensão da escola que vem ganhando cada vez mais ênfase. A eleição de diretores foi adotada por vários sistemas de ensino como iniciativa de democratização da gestão, mesmo antes da promulgação da Constituição Federal, em 1988. Os problemas e as limitaçōes deste processo, apontados em vários estudos, abrangem fatores como excesso de personalismo na figura do 
candidato, falta de preparo de alguns deles, populismo e atitudes clientelistas típicos da velha política partidária, aprofundamento de conflitos entre os segmentos da comunidade escolar, comportamento de apropriação do cargo pelo candidato eleito, dentre outros. Várias legislações, tendo em vista as avaliações decorrentes da implantação de processos eleitorais, introduziram mecanismos reguladores no sentido de diminuir a possibilidade de incidência desses e de outros problemas. Dentre os mais importantes destacam-se a tentativa de despersonalização do poder com a exigência de apresentação de planos de gestão que são debatidos em assembléias de eleitores e o controle das campanhas eleitorais, com adoção de penalidades que chegam à impugnação da candidatura em casos mais graves.

Outro processo de provimento do cargo de diretor identificado pela pesquisa é o que se utiliza de seleção dos candidatos por meio de provas de conhecimento seguida de alguma forma participativa de escolha dos classificados. Todos os sistemas que adotam esse procedimento baseiam-se na necessidade de superar os problemas de competência técnica dos candidatos. As provas de conhecimento seriam o instrumento capaz de selecionar apenas os mais capazes para escolha da comunidade escolar. Esse processo, na visão dos sistemas que o praticam, também permitiria eliminar a interferência política na indicação de diretores. As críticas a esse mecanismo ressaltam o privilegiamento da competência técnica em detrimento da avaliação da liderança política, inclusive porque o professor já teria sua competência profissional aferida no momento em que ingressou na carreira por meio de um concurso público. Há registros, ainda, de que o processo de seleção não tem impedido situações de interferência política na indicação dos diretores escolares.

\section{Implantação e funcionamento de colegiados}

Qualquer que seja o processo de escolha, o diretor permanece sendo uma figura central no esquema de poder que envolve o funcionamento da instituição escolar. Uma das formas de limitação deste poder monocrático é a implantação de colegiados, outro mecanismo largamente utilizado pelos sistemas de ensino como expressão da gestão democrática. A colegialidade foi, como as eleiçōes de diretores, uma prática experimentada pelos sistemas mesmo antes da promulgação da Constituição Federal de 1988. Seu emprego é, em geral, mais aceito que a eleição de diretores, tendo sido, inclusive, incorporado na Lei de Diretrizes e Bases da Educação Nacional como um dos princípios segundo o qual os sistemas 
devem definir suas próprias normas de gestão democrática (Art. 14). Apesar de os colegiados serem constituídos por representaçôes dos diferentes segmentos que compõem a comunidade escolar, há uma visão geral de que essas instâncias organizadas buscam o bem comum e não vantagens e benefícios para as facções representadas. A prática e as avaliações dos próprios sistemas de ensino têm demonstrado, no entanto, que, muitas vezes, os objetivos dos diferentes segmentos não se harmonizam, sendo necessário buscar a formação colegial da decisão por maioria, com o conseqüente compromisso de acatamento por parte dos membros vencidos. Essa situação está longe de configurar-se tranqüila nas unidades escolares, revelando, muitas vezes, a dominação que ainda exercem os docentes sobre os demais segmentos. Há indicações de que a participação de pais em instâncias organizadas externas à escola é capaz de dar outra qualidade ao funcionamento dos colegiados, o que pode indicar a necessidade de uma melhor articulação entre a escola e essas associações da comunidade onde se situam.

A maneira cartorial como são constituídos alguns colegiados tem levado ao seu funcionamento inadequado. Apesar do poder formal que possuem essas instâncias no encaminhamento de diferentes situações da convivência escolar, muitas vezes ele não é exercido por falta de consciência dos conselheiros em relação a esse poder. De toda maneira, apesar das dificuldades decorrentes da implantação e funcionamento dos colegiados escolares, estes são mecanismos capazes de promover o despojamento da dominação de uma só pessoa, superando a monocracia como lógica de funcionamento da direção escolar.

\section{A descentralização}

Parece existir um consenso sobre a necessidade de descentralização no campo da educação pública. É verdade que, se o centralismo administrativo foi um dos fatores que ajudou na implantação da burocracia e na modernização do Estado, no campo da educação esse fenômeno assumiu feições de exagero. Nos sistemas de ensino, o centralismo foi aumentado em um grau tão distante do necessário para permitir a racionalização dos processos administrativos que passou a ser um dos alvos principais das críticas que surgiram em torno da luta pela democratização da educação. É inegável que o centralismo administrativo permitiu a expansão da oferta educacional, mas, exacerbado, tornou a escola distante da comunidade em função do planejamento e da gestão serem realizados em níveis centrais. 
Apesar da descentralização não ser intrinsecamente democratizante, é corrente a confusão conceitual sobre o tema, estabelecendo ligação direta entre a centralização e o autoritarismo, entre a descentralização e a democracia. A municipalização é apontada por vários autores como uma forma possível de superação do centralismo e utilizada como estratégia descentralizadora por alguns sistemas de ensino. No entanto, as análises feitas na pesquisa me permitem considerar que a abordagem da descentralização como municipalização é restritiva, uma vez que pode limitar a discussão sobre gestão educacional aos seus aspectos formais, pouco ou nada acrescentando sobre questóes como a ampliação de processos participativos ou a alteração nas estruturas de poder.

Os dados analisados indicaram que vários sistemas de ensino afirmam a importância da descentralização, mas poucos estabelecem programas para materializá-la. Dentre as diferentes dimensōes da descentralização adotadas nos sistemas - pedagógica, administrativa e financeira - esta última é a forma prevalente. No entanto, a precariedade de recursos faz com que a descentralização financeira transforme-se em administração da escassez, funcionando como fator agravante o fato de que a escola, tida pelo sistema como autônoma, vê-se obrigada a decidir sobre a sua própria privação, isentando o Estado desse desconfortável ônus. Com a falta de infra-estrutura para concretizar a descentralização, instala-se um quadro de abandono no qual a escola é instada a diligenciar no sentido de superar por si mesma suas penúrias materiais. Observo, por isso, que a idéia disseminada de parceria entre a escola pública e setores da comunidade como forma de descentralização e autonomia, ao restringir-se a ações de captação de recursos para provimento das necessidades básicas da instituição escolar, pode aprofundar o fosso que separa escolas de um mesmo sistema, acirrando o perverso afastamento do Estado do financiamento da educação. É natural que, nesse esquema, comunidades melhor aquinhoadas economicamente possibilitem condições materiais especiais às escolas de seus filhos, enquanto aquelas que mais precisam da escola pública como instrumento de equalização de oportunidades tenham menos condição de sustentá-la.

Processos descentralizadores não chegam a transferir poder para as escolas ou promover a articulação das bases locais. Os dados empíricos não demonstram a existência de alterações substantivas nas estruturas administrativas reforçadoras da capacidade de ação das escolas. Enquanto as áreas centrais das administrações não abrirem mão do dirigismo, reduzindo a influência excessiva que exercem sobre a escola, os discursos favoráveis à descentralização, à autonomia e à valorização das unidades 
de ponta dos sistemas, como referência das políticas públicas, continuarão a ser peças de retórica. Apesar de todos os fatores e mecanismos de gestão democrática do ensino público convergirem para a autonomia da escola, esta ainda tem desempenhado um papel periférico nos sistemas. A dependência e o paternalismo ainda são fenômenos que grassam na relação entre a escola e os órgãos superiores da administração. As burocracias centrais e intermediárias, a despeito dos projetos de descentralização e autonomia, expandem-se cada vez mais, dificultando o trabalho das escolas e justificando-se por meio da criação interminável de projetos para serem realizados pelas unidades. Ao lado do excesso de intervenção, a falta de suporte material e logístico atrasa a conquista da autonomia escolar.

\section{A autonomia}

As referências à autonomia escolar nas legislações e normas dos sistemas de ensino são feitas de maneira vaga. De modo geral, enunciam a autonomia como um valor, mas não estabelecem mecanismos concretos para sua conquista efetiva. Medidas de reestruturação burocrática que permitam o funcionamento dos órgãos hierarquicamente superiores a partir das necessidades e projetos gerados pela escola não são apontadas pelos dirigentes dos sistemas. O próprio Regimento Escolar, expressão jurídica por excelência da unidade escolar, é um exemplo de sua falta de autonomia, já que, na maioria dos casos, tem forma única estabelecida pelas administrações centrais e aprovadas pelos órgãos normativos dos sistemas, em flagrante desrespeito às características pedagógicas e culturais específicas de cada escola, na sua relação com as comunidades locais.

O projeto político pedagógico é apontado como expressão coletiva do esforço da comunidade escolar na busca de sua identidade e, nesse sentido, como uma das principais expressões da autonomia escolar. A sua elaboração participativa pode, mesmo, propiciar uma experiência mais conseqüente de outros mecanismos de gestão democrática, como a escolha dos dirigentes e a definição das funções dos colegiados escolares, na medida em que passam a constituir-se referência da ação orgânica de todos os membros da comunidade escolar na busca de objetivos comuns. Apesar disso, e mesmo sendo a elaboração de projetos pedagógicos pelos colegiados uma das atribuiçóes mais consideradas pelas legislaçóes dos sistemas de ensino, não há registros de que as administrações centrais tenham realizado adaptaçôes radicais, no sentido de considerar a escola como centro e razão de ser da existência de sua burocracia. Ao contrário, 
o que se pode verificar pela análise das normas fixadas pelos sistemas de ensino em relação à autonomia escolar é que os documentos são muito parcimoniosos no estabelecimento de mecanismos concretos que caracterizem a faculdade de a escola governar-se por si própria, mas profusos em estabelecer limites que barram a sua autonomia.

\section{III - Dificuldades e resistências aos processos democráticos de gestão}

A pesquisa permitiu concluir que a gestão democrática é uma diretriz de política pública de educação disseminada e coordenada pelos sistemas de ensino. As análises produzidas na pesquisa evidenciam, no entanto, que as dificuldades e as resistências na implantação de processos de gestão democrática ainda são muito intensas. As resistências apontadas pelos próprios agentes do Estado indicam que as forças que agem em contrário ao movimento de democratização da gestão são de diferentes naturezas. ${ }^{9}$ Para alguns, as resistências estão na interferência política sobre a educação. Outros apontam o funcionamento do próprio sistema como um fator limitador da democratização. Nessa linha estão os obstáculos que se relacionam aos complicados processos administrativos, à inflexibilidade na rotina administrativa, ao concentracionismo ou ao autoritarismo arraigado nas relações do sistema com a escola. As resistências dos professores são também consideradas, expressando-se, em geral pelo corporativismo, ao autoritarismo e à formação acadêmica deficiente. Os diretores são apontados como foco de resistência pela sua compreensão equivocada do processo eleitoral, pela centralização de informações e decisões, pelas atitudes corporativas. A própria sociedade, beneficiária legítima da gestão democrática do ensino público, é apontada pelas autoridades como resistentes às iniciativas do Estado. De maneira semelhante, as atitudes de acomodação, desinteresse ou falta de consciência sobre a importância dos processos democráticos produzem focos muitas vezes intransponíveis para a aplicação de mecanismos de gestão participativos.

Como se pode observar, as resistências identificadas pelas autoridades, responsáveis direta ou indiretamente pela administração dos sistemas de ensino, encontram-se no campo da organização e do funcionamento geral do Estado e na relação nem sempre tranqüila de sua elite político-administrativa com os demais atores sociais. $\mathrm{Na}$ visão desses representantes do poder público, a interferência dos coronéis da política, a interrupção de políticas de governo, o excessivo poder dos burocratas, a cultura pouco democrática, o corporativismo dos profissionais, a desconfiança da sociedade em relação ao Estado e suas iniciativas são alguns 
dos fatores que emperram a execução mais profunda de políticas de governo voltadas para a democratização da gestão dos sistemas de ensino. A forma como essas resistências são apontadas, se não expressa um quadro falso da realidade, revela uma observação dos fatos que não abarca o problema em toda a sua amplitude. Refiro-me, aqui, ao fio condutor que está por detrás de todas as dificuldades mencionadas, à lógica furtiva que contamina toda e qualquer iniciativa de modernização e democratização dos sistemas de ensino. Reporto-me à forma patrimonial como está estruturado o Estado, que abarca esses sistemas e que lhes forja a organização, a realização dos movimentos, a dinâmica multidimensional.

\section{IV - Gestão democrática e Estado patrimonial}

Ao destacar a característica patrimonial do Estado brasileiro como eixo explicativo para as resistências aos processos de gestão democrática do ensino público, lembro que não se trata de considerar a existência de um Estado puramente patrimonial, mesmo porque, como assinala Max Weber, o uso terminologicamente correto da expressão patrimonial não dispensa o reconhecimento de que "um Estado 'patrimonial' puro, em sentido absolutamente típico-ideal, nunca existiu historicamente" (Weber, 1991, p. 155).

É inegável que o Brasil experimentou avanços na modernização e na burocratização do Estado. No campo da educação, alguns fatores, dentre outros, podem ilustrar esse esforço modernizador: o estabelecimento de um funcionalismo moderno, com competências oficiais fixas, ordenadas mediante regras; a fixação de uma hierarquia de cargos, como um sistema regulamentado de mando e subordinação das autoridades e fiscalização dos inferiores pelos superiores; a adoção de uma administração baseada em documentos e em um quadro de funcionários, separando o ambiente de trabalho da moradia; a especialização do funcionário na atividade oficial; a administração funcional a partir de ordenamentos fixos e abrangentes que podem ser aprendidos, constituindo-se o seu conhecimento posse dos funcionários. ${ }^{10}$

Essa estrutura burocrática, no entanto, não logrou anular as formas estruturais de dominação não racionais existentes. Nesse sentido, mais que um Estado patrimonial puro, consideram-se os traços, as atitudes e os valores da dominação tradicional que subsistiram no Estado brasileiro, criando um modelo híbrido de burocracia patrimonial. ${ }^{11}$ Traços que se conservam camuflados mesmo no universo capitalista brasileiro. ${ }^{12}$ 
Outros fatores podem ser apontados como elementos dificultadores do processo de burocratização e despatrimonialização no Brasil e, conseqüentemente, fator também impedidor da modernização do Estado brasileiro. ${ }^{13}$ Dentre eles, pode-se destacar a ausência de pessoal qualificado ao qual confiar a administração de governo, sendo as funções desempenhadas por honoráveis locais. ${ }^{14}$

Vai, assim, o Estado brasileiro constituindo-se a partir de um modelo doméstico de relaçôes sociais, onde predominam as vontades particulares mais que as ordenaçôes impessoais que caracterizam o Estado burocrático. Sérgio Buarque de Holanda assinala que a escolha dos homens para exercerem as funções públicas baseou-se mais na confiança pessoal que nas suas capacidades próprias, fugindo, dessa maneira, dos ditames da ordenação impessoal. O funcionário patrimonial pode até chegar a adquirir traços burocráticos, como conseqüência da divisão das funções e da racionalização, mas não chega a constituir-se funcionário burocrático.

No Brasil, pode dizer-se que só excepcionalmente tivemos um sistema administrativo e um corpo de funcionários puramente dedicados a interesses objetivos e fundados nesses interesses. Ao contrário, é possível acompanhar, ao longo de nossa história, o predomínio constante das vontades particulares que encontram seu ambiente próprio em círculos fechados e pouco acessíveis a uma ordenação impessoal (...) as relações que se criam na vida doméstica sempre forneceram o modelo obrigatório de qualquer composição social entre nós. Isso ocorre mesmo onde as instituiçóes democráticas, fundadas em princípios neutros e abstratos, pretendem assentar a sociedade em normas antiparticularistas. (Holanda, 1971, p. 106)

Acentuo a advertência formulada por Holanda de que o modelo particularista medra mesmo nas instituições democráticas, que se apóiam na imparcialidade e na impessoalidade. Dessa maneira, mesmo um sistema de ensino voltado para a implantação de mecanismos participativos, fundado em princípios democráticos, teria dificuldade de funcionar devido ao modelo doméstico que se instalou entre nós na vida social. Esse enraizamento de valores patrimoniais dificultou, sem dúvida, a transição para um modelo de Estado moderno. Burocracia e patrimonialismo imbricam-se, retardando mais ainda o surgimento de uma estrutura estatal que permita a superação do atraso. ${ }^{15}$

As preocupaçôes assinaladas pelas autoridades educacionais em relação à existência de uma burocracia que tudo emperra e dificulta, zelosa dos poderes que amealhou ao longo do tempo, deles não aceitando se apartar, retratam não a burocracia propriamente dita, ${ }^{16}$ mas uma 
camada estamental de domínio alheia ao povo, arraia-miúda cuja participação no jogo político e administrativo é acidental ou suplementar, nunca determinante, pois esse é o papel reservado à comunidade restrita e condutora. ${ }^{17}$ Este grupo formador do quadro administrativo burocráticopatrimonialista constitui o estamento burocrático, ${ }^{18}$ que não se confunde com a burocracia, no sentido que Max Weber assinalou, como estágio mais avançado da dominação racional legal. $\mathrm{O}$ estamento burocrático, ao contrário, gerado no patrimonialismo e bebendo em sua fonte nutrese de seus princípios, acolhendo da burocracia apenas seus procedimentos formais. ${ }^{19}$

Esta caracterização permite compreender um tipo de burocratização pertencente ao Estado não moderno, nascida do patrimonialismo, por ele alimentado e dele alimentador, uma vez que se amolda às mudanças, adotando, tão-somente, aparência de modernidade. $\mathrm{O}$ ajustamento às técnicas modernas, porém, não aproxima o estamento burocrático da burocracia como expressão mais pura da dominação legal e aparelho administrativo que assegura o funcionamento do governo.

É essa maneira autocrática e autoritária de funcionamento do Estado, característica do governo estamental, que permite que as políticas públicas, de que a gestão democrática do ensino público é apenas um exemplo, sejam constantemente alteradas, ao sabor das conveniências políticas. O governante dita à sociedade a sua vontade pessoal como se estatal fosse, numa versão adaptada e moderna do coronelismo, elemento que participa da estrutura patrimonial e que transforma o governante no dono do governo.

Esse poder pessoal acaba permitindo a descontinuidade na sustentação de políticas educacionais, mencionada como fator que dificulta a implantação de mecanismos de gestão democrática. Cada secretário, cada governador ou prefeito tem o seu plano, a sua proposta curricular, a sua lei, julgando, com a arrogância típica de quem se pensa dono do cargo que ocupa, que são os seus instrumentos os que melhor respondem às necessidades da população. ${ }^{20}$ Importante ressaltar que, em relação à questão da descontinuidade na execução de políticas públicas, o problema se localiza na pessoa do governante, mais que no grupo político ou no partido que lhe dá sustentação. Uma análise das políticas educacionais adotadas pelo estado de São Paulo entre os anos de 1967 e 1990, realizada por José Roberto Rus Perez, indicou que, do ponto de vista partidário o Estado teria tido condições de ensejar a continuidade, o que, no entanto, não ocorreu. 
A implementação das políticas públicas esteve, neste período, sob a orientação de apenas dois partidos políticos: ARENA, de 1967 a 1982, e PMDB, de 1983 a 1990. Nessa ótica poderíamos concluir que haveria uma continuidade, um aprendizado, no entanto, em função da fragilidade de nosso sistema partidário tal situação não ocorreu, porque, a cada mudança de gestão, ocorriam desencontros, como se tudo começasse do zero. (Perez, 1994, p. 99)

A permanência de um partido no governo de uma unidade da Federação ou de um município, como se pode depreender da análise do caso precedente, não é condição suficiente para que a continuidade de políticas educacionais seja uma realidade. No entanto, é adequado salientar que esse problema pode, também, estar ligado à natureza dos partidos analisados. Regina Gracindo, num estudo sobre os partidos políticos brasileiros, envolvendo a congruência entre os documentos escritos, as declaraçôes de seus representantes e sua atuação concreta no Congresso Nacional na forma de emendas sobre o ensino fundamental ao projeto de LDB, conclui que o tipo de partido pode ser determinante para a existência ou não dessa coerência. Em relação especificamente à administração educacional democrática, demonstraram ser coerentes em sua doutrina, seu discurso e sua prática apenas os partidos chamados Transformadores. ${ }^{21}$

O Partido Transformador quase não possui conflitos internos a respeito desse tema. Agem, falam e escrevem de forma muito semelhante, revelando a postura mais democrática dos três partidos políticos analisados; de forma geral (excetuando-se a maior parte dos grupos partidários do Partido Transformador), os representantes dos grupos partidários apresentam a sua postura pessoal, revelando pouca ou nenhuma discussão acumulada sobre esse tema nos seus grupos. (Gracindo, 1994, p. 250)

A coerência demonstrada por esse grupo de partidos é um fator que pode minimizar os problemas de descontinuidade na aplicação de políticas públicas de gestão democrática, sendo a averiguação dessa hipótese um campo aberto para novas pesquisas.

A descontinuidade política põe em xeque a visão de que a lei é um instrumento que garante a permanência dos mecanismos de gestão democrática sobre os quais ela dispõe. A posição hierárquica do instrumento legal utilizado na institucionalização de diretrizes políticas na área educacional parece ser um fator indicador da menor ou maior perenidade dessas diretrizes. Parece lógico que quanto mais alta a hierarquia desse instrumento, menos chance de revogação ele teria. Assim, instrumentos jurídicos de caráter unilateral como decretos, portarias, resoluçôes, 
editais teriam mais chances de serem anulados, enquanto a lei, pela natureza de que se reveste, implicando negociações políticas com o parlamento, sofreria menor possibilidade de derrogação. Apesar de esta parecer ser uma análise, em princípio, correta, é preciso considerar que no contexto de um Estado fortemente marcado por ordenamentos patrimonialistas, onde o personalismo do governante exerce a mais forte influência, as casas legislativas muitas vezes atuam, a partir de negociações clientelísticas, como braço do executivo, aprovando praticamente tudo o que por ele é encaminhado e transformando essa importante instância de poder em foro meramente homologatório.

Um caso que pode ilustrar essa relação entre os poderes executivo e legislativo, é o do Distrito Federal. Nessa unidade da Federação, a luta por eleição de diretores data do início dos anos oitenta e sua primeira implantação deu-se no ano de 1985, com o respaldo de um acordo coletivo de trabalho entre o Sindicado de Professores e a Secretaria de Educação. Depois de marchas e contramarchas, a Câmara Legislativa do Distrito Federal aprovou, em 1995, por unanimidade, uma lei de iniciativa do executivo, dispondo sobre a escolha de diretores por meio de eleição direta. $\mathrm{O}$ processo, no entanto, não durou mais que um período de governo, uma vez que o novo governante, ${ }^{22}$ a partir da argumentação de que as eleições supostamente não permitem avaliar a competência dos candidatos, enviou ao parlamento local outra lei abolindo as eleiçōes e adotando concurso interno para elaboração de lista tríplice para livre escolha do governador. A lei aprovada ${ }^{23}$ instalou um procedimento denominado de gestão democrática sem precedentes no país, por meio do qual o governante pode usar de artifícios para nomear quem bem entender ${ }^{24}$ apresentando como democrático um processo que exclui a participação da comunidade escolar, como racional e burocrático o que é patrimonial, como impessoal o que pode ser dirigido para atender a uma clientela determinada.

Esse é um típico exemplo de conformação do patrimonialismo às técnicas racionais e democráticas, que pode explicar por que motivo a gestão democrática pode existir no complexo das normas racionais-legais de um sistema de ensino e não funcionar no mundo real controlado por ordenamentos patrimonialistas. A dimensão patrimonial continua, assim, como característica predominante do Estado brasileiro, como uma forma de dominação política adaptada, decorrente de um tipo de transição para a modernidade que se fez comprometida com a convivência entre uma sociedade fraca e um aparelho administrativo forte. ${ }^{25}$ 
Se no Estado brasileiro em geral a presença dos valores patrimoniais é marcante, no campo educacional, em particular, essa presença se dá também pela característica acentuadamente doméstica das relaçôes sociais que se travam no ambiente escolar. ${ }^{26}$ Também na escola, um jogo de forças burocráticas e patrimoniais revela-se em permanente tensão. Ao esforço de modernização e de implantação de normas racionais legais contrapóe-se a resistência de forças tradicionais. $\mathrm{O}$ arcabouço legal que regula o sistema e o conjunto dos seus órgãos administrativos aproximamse da característica burocrática, mas os sujeitos concretos que os sustentam e lhes dão vida continuam regidos por valores tradicionalistas. ${ }^{27}$ É no comportamento do professor, de maneira particular, que essa contradição se acentua, conformando um modelo patrimonial de pouca distinção entre o público e o privado que permite que esse segmento hegemônico se aproprie da instituição e de seus membros como se deles fosse dono. ${ }^{28}$

A escola reflete, assim, o ambiente mais amplo da sociedade, onde os usuários, cidadãos comuns, têm sua participação limitada a eventos como uma assembléia, uma eleição, uma e outra reunião onde opinam sobre assuntos em geral pouco relevantes, como caudatários de uma cidadania fluida e sem maiores conseqüências. ${ }^{29}$ Registro, no entanto, que a Constituição Federal promulgada em 1988 e responsável pela existência legal da gestão democrática como princípio do ensino público, apesar de hoje bastante mutilada por emendas aprovadas em nome da governabilidade, ${ }^{30}$ foi caracterizada como "Constituição Cidadã", por ter sido elaborada mais na perspectiva do cidadão que do Estado. Instalase, assim, um quadro de constitucionalismo nominal ${ }^{31}$ revelado pelo paradoxo, cuja base é a existência de um Estado patrimonial com a vigência de uma Constituição elaborada na perspectiva do cidadão, impondo preceitos que não se adaptam ao processo político.

O Estado patrimonialista, em seu gigantismo, seu centralismo e em sua função empreendedora de produtor da riqueza da nação, tudo abarca, à custa do enfraquecimento da sociedade e do fortalecimento dos estamentos que o dominam. O patrimonialismo constitui a terra seca e infértil de um tipo de Estado que inibe a germinação das sementes da participação, na qual se funda a democracia.

A grave questão que se coloca em relação à construção e ao aprofundamento da cidadania num país como o Brasil está em como controlar o poder de um Estado que foi formado nessa perspectiva sem cair no falacioso discurso da miniaturização do Estado, que tem servido tão-somente para afetar a soberania do Estado nação em favor de processos 
globalizados de implantação de mercados sem pátria. No entanto, a democracia que adjetiva a gestão do ensino público como princípio constitucional não existe sem uma sociedade nacional. ${ }^{32}$

A reação dos sistemas de ensino brasileiros ao imperativo da Constituição Federal de 1988 de concretizar a gestão democrática como princípio do ensino público denuncia a permanente tensão em que vive o Estado brasileiro, entre a modernização e o arcaísmo de suas estruturas. Tensão que se revela na luta entre o direcionamento do Estado à burocratização, imposto pelas normas racionais-legais, e a teimosa permanência dos valores patrimonialistas, imposto pela tradição enraizada na política e nos costumes. Revela a separação entre a intenção e o gesto, expondo a distância existente entre as regras definidas pelos instrumentos burocráticos do Estado e a ação concreta que é praticada pelos seus diferentes agentes.

Recebido para publicação em junho de 2001.

Notas

1. Esse texto é resultado de trabalho apresentado na $23^{a}$ Reunião Anual da Anped, em Caxambu (MG), set. 2000.

2. A pesquisa, intitulada "A regra e o jogo: Democracia e patrimonialismo na educação brasileira" (Mendonça, 2000) foi desenvolvida no âmbito do Programa de Doutorado em Educação da Unicamp, sob orientação acadêmica do Prof. Dr. Newton Antonio Paciulli Bryan.

3. A sugestão de roteiro constou, basicamente, das seguintes solicitaçôes: envio de documentos que retratassem a concepção de gestáo democrática adotada pelo sistema; identificação dos períodos de governo em que os mecanismos de gestão democrática apontados foram implantados; identificação da adoção de mecanismos de gestão democrática anteriores à Constituição Federal de 1988; identificação do mecanismo utilizado para escolha dos diretores de escolas públicas e dos documentos legais que o normatizam; indicação sobre existência de colegiados democraticamente constituídos nas diversas instâncias do sistema de ensino; identificação de políticas de descentralização; identificação de medidas criadas pelo sistemas de ensino para facilitar a participação da comunidade escolar; identificação de mecanismos de controle das políticas públicas educacionais pela sociedade civil; identificação de resistências aos processos de gestão democrática; outras informaçōes consideradas relevantes.

4. Desse conjunto, a maior incidência de respostas deu-se no âmbito do executivo, de modo que 17 das 27 Secretarias Estaduais de Educação, ou 62\%, e 19 das 26 Secretarias Municipais de Educação, ou $73 \%$, atenderam à solicitação formulada pela pesquisa. No âmbito do legislativo, responderam a consulta, 9 das 27 Assembléias Legislativas, ou 33\%, e 9 das Câmaras Municipais, ou 34\%. Dos 27 Conselhos Estaduais de Educação instalados no país, 9 atenderam à solicitação, atingindo um índice de $33 \%$. Tomando por base os níveis estadual e municipal, das 81 respostas solicitadas às instâncias das Unidades da Federação, 35, ou 43\%, foram atendidas; das 52 solicitaçôes encaminhadas aos municípios das capitais, 28, ou 54\% foram respondidas. Como é possível observar, os índices de atendimento às consultas variaram entre $33 \%$ e $73 \%$. Nenhuma região geográfica do país deixou de ser contemplada com um índice de 
respostas significativo e apenas o estado do Pará ficou a descoberto, considerando que nenhuma das três instâncias estaduais nem das duas instâncias do município de sua capital atenderam à solicitação.

5. A tentativa de responder a essa questão exigiu a elaboração de um quadro teórico baseado na categoria weberiana de patrimonialismo e nas obras de autores que, inspirados por essa leitura, geraram importantes análises sobre o processo de formação brasileira, das quais se destacam as obras de Faoro (1993, 1995 e 1997), sobre a formação do patronato político brasileiro; Holanda (1971), com o clássico Raízes do Brasil; Uricoechea (1978) sobre a burocratização do Estado patrimonial no século XIX; Schwartzman (1988), sobre as bases patrimonialistas do autoritarismo brasileiro; Paim (1994) sobre o estatismo brasileiro e sua relação com o patrimonialismo.

6. AC, ES, RS, DF e município de Cuiabá/MT.

7. Silva (1989) analisa a participação como política de governo e sua viabilidade na estrutura administrativa do sistema de ensino paulista; Hora (1994) estuda a mobilização social pela implantação de uma escola estruturada para ter a participação como diretriz central; Cardoso (1995) analisa a participação em uma escola comunitária; Ghanen Júnior (1992) analisa as lutas populares de um bairro da cidade de São Paulo e sua influência sobre a participação na escola; Frem (1989), Corrêa (1991) e Carvalho (1989) descrevem e analisam os obstáculos à participação em escolas de Campinas (SP); Avancine (1990) analisa a participação das mães em uma escola estadual da cidade de São Paulo; Paro (1992) aponta problemas e perspectivas sobre a participação da comunidade em estudo de caso de uma escola na mesma cidade.

8. Para referências a respeito de eleição de diretores ver, entre outros: Dourado (1990) e Canesin (1993) sobre GO; Homesland et al. (1989) e Leal \& Silva (1987) sobre SC; Heeman (1986) e Gonçalves (1994) sobre o PR; Castro \& Werle (1991) sobre o RS; Werle (1991) sobre RS, SC e PR; Paixão (1994) sobre MS; Mendonça (1987) e Couto (1988) sobre o DF; Calaça (1993) sobre o município de Goiânia. Paro (1996) faz uma análise das experiências de eleição no país. Dourado \& Costa (1998) identificam as modalidades de escolha de dirigentes escolares nas esferas dos estados e dos municípios das capitais.

9. O roteiro recebido pelos titulares das instâncias executiva, legislativa e normativa dos estados, do DF e dos municípios das capitais apresentou o seguinte questionamento: "que principais resistências ao processo de gestão democrática do ensino público podem ser apontadas no âmbito desse sistema de ensino?".

10. Ver, nesse sentido, o Capítulo IX - Sociologia da Dominação, em especial a Seção 2 - Natureza, pressupostos e desenvolvimento da dominação burocrática (Weber, 1999, p. 198-233).

11. Fernando Uricoechea já chamava atenção para a existência histórica dessa matriz peculiar, nos seus estudos sobre o Estado brasileiro no século XIX: "É justamente nessa coexistência antagônica e conflitante de formas tradicionais e racionais, de patrimonialismo e burocracia, que repousa um dos traços mais peculiares da organização institucional da comunidade política brasileira do século XIX” (1978, p. 302).

12. "A presença do patrimonialismo se prova pela história, uma história que começa em Portugal e ainda está em curso. Ele vive, atua, se dissimula e emerge debaixo de uma máscara capitalista" (Faoro, 1993, p. 25).

13. Brum Torres (1989) considera a despatrimonialização, junto com a consolidação da idéia de soberania e a despersonalização do poder como elementos balizadores do surgimento do Estado moderno.

14. Em relação a essa dificuldade, Fernando Uricoechea afirma que "quisesse ou não, o Estado viuse precisado de lançar mão de meios patrimoniais para o preenchimento desses serviços" (Uricoechea, 1978, p. 113). 
15. Simon Schartzmann indicou esse como um problema efetivo da transição por que passou o Estado brasileiro: “o problema crucial dos Estados contemporâneos de origem burocráticopatrimonialista é de como fazer a transição de uma estrutura ineficiente, pesada e embebida por um sistema de valores ultrapassado e conservador, para uma estrutura ágil, moderna e capaz de levar a efeito, finalmente, a passagem do subdesenvolvimento e atraso ao desenvolvimento e justiça” (1988, p. 10).

16. A expressão "burocracia" é amplamente utilizada nos documentos dos sistemas de ensino com o sentido diverso da modernização e adoção de normais racionais legais, fatores característicos da dominação legal, tal como a utiliza a teoria weberiana. A conotação dada ao termo por esses documentos aproxima-se do sentido de complicação ou morosidade do serviço administrativo, má circulação de papéis, inflexibilidade de rotina administrativa.

17. “Os países aprisionados pelo estamento se modernizam, ocidentalizando-se, por via de um plano do alto, imposto à nação, com a teorização, retardada de muitas décadas, de processos espontâneos nas sedes criadoras. O mundo se parte em mundo metropolitano, diretor e condutor, e mundo de retaguarda, alheando ainda mais a minoria do conjunto da nação" (Faoro, 1997, p. 93).

18. "Sobre as classes que se armam e se digladiam, debaixo do jogo político, vela uma camada político-social, o conhecido e tenaz estamento, burocrático nas suas expansões e nos seus longos dedos" (Faoro, 1997, p. 387).

19. "Há a burocracia, expressão formal do domínio racional, própria ao Estado e à empresa modernos, e o estamento burocrático, que nasce do patrimonialismo e se perpetua noutro tipo social, capaz de absorver e adotar as técnicas destes, como meras técnicas. Daí seu caráter não transitório" (Faoro, 1995, p. 738).

20. Luiz Antônio Cunha denomina esse padrão de gestão das redes públicas de ensino de "administração zig-zag", apontando duas conseqüências diretas de sua aplicação: a impossibilidade de avaliação das políticas educacionais pela falta de tempo de maturação e a desconfiança desenvolvida pelos professores diante das mudanças a cada início de gestão. Dessa maneira, políticas bem conduzidas de educação acabam sendo demolidas por administrações interessadas em imprimir sua própria marca. "Desenvolvem uma sadia resistência diante dos intentos mudancistas, já que não sabem quanto tempo vão durar. Uma conseqüência derivada é que esse hábito de resistir às mudanças inconseqüentes acaba por se fixar e fazer com que não se aceite até mesmo as políticas educacionais mais sadias e apropriadas" (Cunha, 1995, p. 475).

21. Os grupos partidários que fazem parte da categoria de Partido Transformador são o Partido Comunista do Brasil - PC do B, o Partido Popular Socialista - PPS, o Partido Socialista Brasileiro - PSB, o Partido dos Trabalhadores - PT e o Partido Verde - PV. Outras categorias apontadas pela autora são os partidos invariantes (PDC, PDS, PFL, PRN, PSC, PTB e PTR), partidos mudancistas (PDT, PL, PMDB, PRS, PSDB e PST). A tipologia adotada considerou apenas os 18 partidos com assento no Congresso nacional, dentre os $41 \mathrm{com}$ registro no Tribunal Superior Eleitoral.

22. Joaquim Roriz - PMDB

23. Distrito Federal: Lei Complementar 247/99.

24. A lei determina que pode se inscrever qualquer professor vinculado ao sistema de ensino há, pelo menos, cinco anos, sem nenhuma exigência de que o mesmo tenha atuado na escola que pretende dirigir, o que dá uma margem de manobra muito grande ao governo que pode, por exemplo, influenciar professores a se inscreverem no processo, instalando-se um jogo de cartas marcadas. Além do mais, a lei estabelece, ainda, que o processo só tem validade se quatro candidatos se inscreverem em cada escola, freqüência historicamente muito difícil de ser alcançada. Caso contrário, dá-se a livre indicação de um diretor pro-tempore até que nova seleção seja realizada.

Educação \& Sociedade, ano XXII, no 75, Agosto/2001 
25. Essa é uma das teses centrais do estudo de Simon Scwartzmann sobre as raízes do autoritarismo brasileiro (Scwartzmann, 1988).

26. Raquel Gandini chama atenção para esse fato, dando como exemplo que reflete a não superação dos relacionamentos patrimonialistas na convivência pedagógica o tratamento que utiliza termos que traduzem parentesco onde não existe: “Traços e concepções de ordem tradicional patrimonial se mostram ainda bastante acentuados, tanto em nossos relacionamentos políticos, como sociais e, em particular, naqueles propriamente 'domésticos' como é o caso dos relacionamentos familiares e educacionais” (Gandini, 1997, p. 56).

27. Luiz Pereira, na análise sociológica de uma escola primária pública da cidade de São Paulo, observa que as normas são um modelo organizatório burocrático, já que regulamentam deliberadamente a vida da escola, mas os padrôes de comportamento e valores tomados como modelo de conduta agem como força antiburocrática: "A discrepância entre o Regimento Interno e aspectos reais da vida daquela escola, aos quais se aplicam as normas do Regimento, fornecem índices de burocratização daquele grupo social" (Pereira, 1967:62).

28. Traços tradicionalistas e de ordem burocrática convivem no comportamento do professor, na visão de Luiz Pereira: “Tal acomodação entre elementos tradicionais e burocráticos resulta da atual fase de semiburocratização do magistério primário, na qual os professores já se apegaram às compensações burocráticas da profissão, mas não aceitam integralmente as responsabilidades que o Regimento lhes impõe” (1967, p. 80). Apesar de passados mais de 30 anos da publicação da pesquisa do autor e de sua análise centrar-se na questão do Regimento Escolar como instrumento racional-legal, suas afirmações podem ser aplicadas ao arcabouço mais amplo da legislação educacional e continuam verdadeiras para os padrões de burocratização da profissão do professor de escola pública no Brasil. Ainda em relação ao professor, afirma o autor que "os desvios de seu comportamento aparecem como produtos das inconsistências internas da escola primária e como característicos de uma profissão semiburocratizada, na qual as motivações racionais-legais ainda se mostram incapazes de substituir completamente as motivaçôes não burocráticas que entraram em decadência” (idem, p. 84-85).

29. Brum Torres (1989, p. 31), citando Benjamin Constant, lembra que "Perdidos na multidão, o indivíduo já quase não percebe a influência que exerce nem vê nunca sua vontade marcar o conjunto: nada comprova para seus próprios olhos sua cooperação" (Constant, De la liberté chez les modernes. Écrits politique, Paris: Librairie Générale Française, 1980, p. 501).

30. É digna de nota a concepção manifestada pelo governo do MT, ao encaminhar à Assembléia Legislativa daquele estado a Mensagem 27/96, acompanhando um projeto de lei sobre Carreira do Magistério. Considerando que a Constituição Federal de 1988 gerou compromissos difíceis ou inviáveis de serem cumpridos pelos governos, afirma que "acolhendo aspiraçóes e interesses de diversos segmentos da sociedade, sem a necessária avaliação da efetiva possibilidade de ação governamental, a Constituição gerou compromissos que ampliam em muito a complexidade da gestão da Educação".

31. “(...) o regime autoritário convive com a vestimenta constitucional, sem que a lei maior tenha capacidade normativa, adulterando-se no aparente constitucionalismo - o constitucionalismo nominal, no qual a Carta Magna tem validade jurídica mas não se adapta ao processo político, ou o constitucionalismo semântico, no qual o ordenamento jurídico apenas conhece a situação de poder dos detentores autoritários" (Faoro, 1995, p. 741).

32. "A democracia diz respeito ao povo de uma nação, à sociedade nacional, ao modo de relacionamento entre a sociedade civil e o Estado, à forma do Estado-Nação (...). Sob todos os aspectos, a democracia (...) compreende o Estado-Nação" (Ianni, 1993, p. 87). 


\section{Patrimonial State and democratic management}

OF PUBLIC EDUCATION IN BRAZIL

ABSTRACT: This article approaches the democratic management of public education in Brazil. It seeks to assess how the education systems of the States, the Federal District, and State capitals have been organized to meet the constitutional provisions that established democratic management as a public education principle, and at which level they adapted their legislation and rules, as well as their administrative framework, to participation demands. It analyzes the democratic management concepts vis-à-vis participation, principals assignment processes, the constitution and functioning of support committees within the schools, decentralization, and autonomy. It also mentions recent studies and research on the efforts and resistances found in the implementation of democratic management mechanisms in different education systems. It builds on the fact that the democratic management is adopted by the State as a means to achieve strategic targets and analyses the difficulties resulting from the implementation of such mechanisms, since these presuppose a high level of social participation but are sponsored by a State model strongly characterizes by patrimonialistic arrangements.

Key words: Education and State; Patrimonialism; Democratic management.

\section{Referências bibliográficas}

AVANCINE, Sérgio. Daqui ninguém nos tira: Mães na gestão colegiada da escola pública. Dissertação de Mestrado, PUC-SP, São Paulo, 1990.

CALAÇA, Celina Ferreira. Eleição de diretor de escola e gestão democrática: Um estudo de caso. Dissertação de Mestrado, PUCSP, São Paulo, 1993.

CANESIN, Maria Tereza. Um protagonista em busca de interlocução: Um resgate da história do movimento de professores da rede pública de $1^{\circ}$ e $2^{\circ}$ graus em Goiás, na conjuntura 1979/1989. Tese de Doutorado, PUC-SP, São Paulo, 1993.

CARDOSO, Aparecida. Gestão participativa na escola comunitária. Dissertação de Mestrado, Unicamp, Campinas, 1995.

CARVALHO, Marília Pinto de. Um invisível cordão de isolamento: Escola e participação popular. Cadernos de Pesquisa, São Paulo, ago. 1989, no 70, p. 65-73. 
CASTRO, Marta Luz Sisson de \& WERLE, Flávia Obino Corrêa. Eleiçôes de diretores: Reflexôes e questionamento de uma experiência. Estudos em Avaliação Educacional, São Paulo, jan./jun. 1991, 3, p. 103-112,

CORRÊA, Rosa Lydia Teixeira. Administração participativa: Realidade ou mito? Campinas: Dissertação de Mestrado, Unicamp, Campinas, 1991.

COUTO, Jurema Barbieri. Gestão democrática na escola pública: $\mathrm{O}$ caso do Distrito Federal (1985-1988). Dissertação de Mestrado, UnB, Brasília, 1988.

CUNHA, Luiz Antônio. Educação, Estado e democracia no Brasil. São Paulo: Cortez; Niterói: Editora da UFF; Brasília: Flacso do Brasil, 1995.

DOURADO, Luís Fernandes \& COSTA, Messias. Escolha de dirigentes escolares no Brasil. Relatório Final de Pesquisa. Brasília: Anpae, 1998.

DOURADO, Luís Fernandes. Democratização da escola: Eleições de diretores, um caminho? Dissertação de Mestrado, UFG, Goiânia, 1990.

FAORO, Raymundo. A aventura liberal numa ordem patrimonialista. Revista da USP, São Paulo, mar./maio 1993, 17, p. 14-29.

. Os donos do poder: Formação do patronato político brasileiro. São Paulo: Globo, vol. I, 1997; vol. II, 1995.

FREM, Sandra A. Obstáculos e possibilidades para uma gestão democrático-participativa na escola estadual de $1^{\circ}$ grau. Dissertação de Mestrado, Unicamp, Campinas 1989.

GANDINI, Raquel Pereira Chainho. Patrimonialismo e educação: A autoridade do professor em discussão (homenagem a Luiz Pereira). Campinas, dez. 1997 (mimeo).

GHANEM JR., Elie G.G. Lutas populares e qualidade da escola pública. Dissertação de Mestrado, USP, São Paulo, 1992.

GRACINDO, Regina Vinhaes. $O$ escrito, o dito e o feito: Educação e partidos políticos. Campinas: Papirus, 1994.

HEEMAN, Eliane Barbosa. A eleição dos diretores das escolas estaduais do Paraná e seus efeitos na vida da escola. Revista Brasileira de 
Administração da Educação, Porto Alegre, jul./dez. 1986, 4(2), p. 46-62.

HOLANDA, Sérgio Buarque de. Raizes do Brasil. Rio de Janeiro: Livraria José Olympio Editora/INL-MEC, 1971.

HOLMESLAND, Içara da Silva et al. A liderança nas escolas na nova democracia social: uma análise interestadual. Relatório de Pesquisa, PUC-RS, Porto Alegre, 1989.

HORA, Dinair Leal da. Gestão democrática da escola: Artes e ofícios da participação coletiva. Campinas: Papirus, 1994.

IANNI, Octavio. O labirinto latino-americano. Petrópolis: Vozes, 1993.

LEAL, Elisabeth Juchem Machado \& SILVA, Virgínia Maria de Figueiredo e. Diretores eleitos: Dilemas emergentes da greve do magistério de 1987 em Santa Catarina. Revista Brasileira de Administração da Educação, Porto Alegre, jan./jun. 1987, 5(1), p. 62-77.

MENDONÇA, Erasto Fortes. A eleição de diretores do ensino público do DF: Avanço ou manipulação? Revista Brasileira de Administração da Educação, Porto Alegre, jul./dez. 1987, 5(2), p. 49-62.

. A regra e o jogo: Democracia e patrimonialismo na educação brasileira. Campinas: Edições Lapplane, Unicamp, 2000.

MONTENEGRO, Neisse Fernandes. O conselho de escola e a gestão participativa. Dissertação de Mestrado, PUC-SP, São Paulo, 1991.

PAIM, Antonio. A querela do estatismo. A natureza dos sistemas econômicos: O caso brasileiro. Rio de Janeiro: Tempo Brasileiro, 1994.

PAIXÃO, Regina da. "O colegiado escolar como instrumento de gestão participativa: A vivência de Mato Grosso do Sul”. In: XAVIER, Antonio Carlos da R., Sobrinho, José Amaral \& Marra, Fátima (Orgs.), Gestão escolar: desafios e tendências. Brasília: IPEA, 1994, p. 107122.

PARO, Vitor Henrique. Eleição de diretores: A escola pública experimenta a democracia. Campinas: Papirus, 1996.

. Gestão da escola pública: A participação da comunidade. Revista Brasileira de Estudos Pedagógicos, Brasília, maio/ago. 1992, 73(174), p. 225-290. 
PEREIRA, Luiz. A escola numa área metropolitana: Crise e racionalização de uma empresa pública de serviços. São Paulo: Livraria Pioneira Editora/ Edusp, 1967.

SAVIANI, Dermeval. A nova lei da educação: Trajetória, limites e perspectivas. Campinas: Autores Associados, 1997.

SCHWARTZMAN, Simon. Bases do autoritarismo brasileiro. Rio de Janeiro: Campus, 1988.

SILVA, Igínia Caetana Finelli. Orientações participativas descentralizadoras: Uma (in)viabilidade na estrutura administrativa do ensino de $1^{\circ}$ grau. Dissertação de Mestrado, Unicamp, Campinas, 1989.

TORRES, João Carlos Brum. Figuras do Estado moderno: Representação política no Ocidente. São Paulo/Brasília: Brasiliense/CNPq, 1989.

URICOECHEA, Fernando. O minotauro imperial: A burocratização do Estado patrimonial brasileiro no século XIX. Rio de Janeiro/São Paulo: Difel, 1978.

WEBER, Max. Economia e sociedade: Fundamentos da sociologia compreensiva. Brasília: Editora da UnB, vol. I, 1991; vol. II, 1999.

WERLE, Flávia Obino Corrêa. Estado e a política de eleição de diretores do Rio Grande do Sul, Santa Catarina e Paraná. Educação \& Realidade, Porto Alegre, jul./dez. 1991, 16(2), p. 35-45. 